\title{
Outcomes of the national programme on prevention of mother-to-child transmission of hepatitis B virus in China, 2016-2017
}

Ya-Ping Qiao ${ }^{1}$, Min Su${ }^{1}$, Yao Song ${ }^{2}$, Xiao-Yan Wang ${ }^{1}$, Zhen Li ${ }^{1}$, Yan-Lin Li ${ }^{3}$, Li-Xia Dou', Qian Wang ${ }^{1}$, Katrina Hann ${ }^{4}$, Guo-Min Zhang ${ }^{5}$, Xiao-Na Huang ${ }^{6}$, Yu-Ning Yang ${ }^{6}, X_{i}$ Jin $^{1}$ and Ai-Ling Wang ${ }^{1 *}$ (D)

\begin{abstract}
Background: In addition to providing free hepatitis B vaccine (HBvacc) series to all infants in China since 2005, the national programme on prevention of mother-to-child transmission (PMTCT) of hepatitis B virus (HBV) started providing free hepatitis B immunoglobulin for all new-borns born to hepatitis B surface-antigen (HBsAg) positive mothers in 2010. However, few studies have evaluated the effectiveness of the PMTCT programme. Therefore, we aimed to investigate the outcomes of the programme and identify associated factors.
\end{abstract}

Method: Using a cross-sectional study design, we collected data on 4112 pairs of HBsAg-positive mothers and their children aged 7-22 months in four representative provinces through interviews and medical record review. We tested HBsAg and hepatitis B surface antibody (anti-HBs) of children by enzyme-linked immunosorbent assay at designated maternal and child hospital laboratories. We used logistic regression to analyse factors associated with child HBsAg and anti-HBs positivity.

Results: Thirty-five children were HBsAg positive, indicating the mother-to-child transmission (MTCT) rate was 0.9\% (0.6-1.1\%). The anti-HBs positive rate was 96.8\% (96.3-97.4\%). Children receiving HBvacc between 12 and $24 \mathrm{~h}$ of birth were 2.9 times more likely to be infected than those vaccinated in less than $12 \mathrm{~h}$ (adjusted odds ratio $[a O R]=2.9,95 \%$ confidence interval [C]: 1.4-6.3, $P=0.01$ ). Maternal hepatitis B e-antigen ( $\mathrm{HBeAg}$ ) positivity was associated with higher MTCT rate $(a O R=79.1,95 \% \mathrm{Cl}: 10.8-580.2, P<0.001)$ and lower anti-HBs positive rate $(\mathrm{aOR}=0.4,95 \% \mathrm{Cl}: 0.3-0.6$, $P<0.001)$. Children with low birth weight (LBW) were $60 \%$ less likely to be anti-HBs positive than those with normal birth weight (aOR=0.4, 95\% Cl: 0.2-0.8, $P=0.01)$.

Conclusions: The MTCT rate was lower than the 2030 WHO elimination goal, which implies the programme is on track to achieve this target. As earlier HBvacc birth dose (HBvcc-BD) was associated with lower MTCT rate, we suggest that the PMTCT programme work with the Expanded Programme on Immunization (EPI) to modify the current recommendation for early HBvcc-BD to a requirement. Our finding that LBW was associated with lower anti-HBs positivity points to the need for further studies to understand factors associated with these risks and opportunities for program strengthening. The programme needs to ensure providing essential test to identify HBeAg-positive mothers and their infants and provide them with appropriate medical care and follow-up.

Keywords: Perinatal, Birth dose, Immunization, elimination, Vaccination guideline

\footnotetext{
* Correspondence: maternal2019@163.com

${ }^{1}$ National Centre for Women and Children's Health, China CDC, Beijing, China

Full list of author information is available at the end of the article
}

(c) The Author(s). 2019 Open Access This article is distributed under the terms of the Creative Commons Attribution 4.0 International License (http://creativecommons.org/licenses/by/4.0/), which permits unrestricted use, distribution, and

reproduction in any medium, provided you give appropriate credit to the original author(s) and the source, provide a link to the Creative Commons license, and indicate if changes were made. The Creative Commons Public Domain Dedication waiver (http://creativecommons.org/publicdomain/zero/1.0/) applies to the data made available in this article, unless otherwise stated. 


\section{Multilingual abstracts}

Please see Additional file 1 for translations of the abstract into the five official working languages of the United Nations.

\section{Background}

Hepatitis B is a global public health concern with 257 million people living with hepatitis $B$ virus ( $\mathrm{HBV}$ ) infection (hepatitis B surface-antigen [HBsAg] positive) worldwide [1]. The Western Pacific region accounted for almost $45 \%$ of the total number of 257 million globally [1]. Without intervention, the mother-to-child transmission (MTCT) risk in Asia for infants born to mothers with only HBsAg positivity and with both $\mathrm{HBsAg}$ and hepatitis $\mathrm{B}$ e-antigen (HBeAg) positivity is high, 5-30\% and $70-100 \%$ respectively [1]. Globally, the proportion of children under 5 years who become chronically infected has dramatically declined from $4.7 \%$ in the prevaccine era (prior to the 1980s) to $1.3 \%$ in 2015 because of the expansion of routine hepatitis $B$ vaccination [1]. The World Health Organization (WHO) has subsequently set a global target to achieve a $0.1 \%$ prevalence of HBV infection in children by 2030, with associated objectives to prevent MTCT through expanding the coverage of Hepatitis $B$ vaccine birth dose (HBvacc-BD) to $90 \%$ of infants [2-4].

It is estimated that more than 90 million persons are chronically infected with $\mathrm{HBV}$ in China [5]. Annually about 100000 persons are newly infected with HBV, among which $40-50 \%$ are infected through vertical transmission [6]. The Chinese Central Government started to provide free three-dose hepatitis B vaccines (HBvacc) for all infants through the nation-wide Expanded Programme on Immunization (EPI) in 2005, guided by the National Immunization Schedule [7, 8]. These efforts have resulted in reductions in HBsAg-positive prevalence in both the general population (9.2 to $7.2 \%$ from 1992 to 2006) and children under 5 years (0.96 to $0.32 \%$ from 2006 to 2014) [7].

While the results of EPI are laudable, hepatitis transmission still persists. The MTCT rate among HBV-exposed infants ranges from 3 to $5 \%[9,10]$, with approximately 50 000 infants infected annually in China $[7,11]$. In 2013, the HBsAg prevalence among pregnant women was 6\% [12]. Hence, there were about 1 million such deliveries annually at risk of MTCT. Among those deliveries, 30\% of infants are born to HBsAg- and HBeAg-positive mothers with high MTCT risk [5].

As HBV MTCT remains an important public health concern in China, the national programme on prevention of mother-to-child transmission (PMTCT) of human immunodeficiency virus (HIV) integrated syphilis and HBV into its mandate in 2010. The programme, which covers all women accessing antenatal care services across the country, now tests all women for HBsAg during pregnancy and administers hepatitis B immunoglobulin (HBIG) and HBvacc-BD for all HBV-exposed new-borns within $24 \mathrm{~h}$ of birth free-of-charge [13]. In addition, China endorsed the 2018-2030 Asia Pacific Regional Framework for Triple Elimination of MTCT of HIV, syphilis and HBV in 2017 [14]. However, despite these important programmatic and policy actions, the outcomes of HBV component of the PMTCT programme have not yet been systematically evaluated. Identifying the current HBV MTCT rate will allow for projections and target setting in relation to the global and regional elimination goals. In addition, understanding factors associated with programmatic outcomes is essential to better understand how to make policy and programmatic recommendations that ensure services reach the 'last mile' of mother-infant pairs. Therefore, our study aimed to investigate the outcomes and associated factors of the HBV component of the national PMTCT programme in China between 2016 and 2017 .

\section{Methods \\ Study design}

We conducted a cross-sectional study in four representative provinces of China between October 2017 and January 2018. We chose Guangdong, Zhejiang, Shaanxi, and Hebei province representing different levels of the prevalence of HBsAg positivity among pregnant women in China as well as representation across the regions. Among those four provinces, Zhejiang and Guangdong located in eastern China, Hebei located in central China, and Shaanxi located in western China. We selected two to five counties per province based on the highest estimated number of HBV-exposed infants to reach to ensure that we included a substantial number of mother-child pairs. We applied a two-prong approach to collect the data. The study team used a structured-questionnaire to collect maternal demographics, laboratory test to identify serological outcomes of HBV-exposed children, and reviewed the medical records of the mother-child pairs and immunization records of the children to extract data on maternal laboratory test results, delivery, and immunoprophylactic management of children. In addition, we reported this study following the STROBE guidelines [15].

\section{General setting}

The national programme on PMTCT of HIV, syphilis, and HBV, funded by the Chinese Central Government, started in 2010 in 41\% (1156 of 2851) of counties and districts and expanded nation-wide in 2015. In addition to preventing vertical transmission of HIV and syphilis, the programme aims to reduce the HBV MTCT rate through screening of pregnant women and timely HBIG provision for $\mathrm{HBV}$-exposed new-borns. The PMTCT 
programme works closely with the EPI to reinforce effective coverage of the three-dose Hepatitis $B$ vaccination schedule for HBV-exposed infants (see Table 1 for details of the programme intervention components and associated indicators). According to the national action plan [13] and the 2005 Standard for Vaccination Work Specification [16], prophylaxis for infants born to HBsAg-positive women consists of HBvacc and HBIG administered within $24 \mathrm{~h}$ of birth, followed by completion of the vaccine series. In line with WHO recommendations, the HBvacc-BD is required within $24 \mathrm{~h}$ of birth, but strongly recommends HBV-exposed infants receive it as soon as possible following birth [8].

\section{Study population}

We defined inclusion criteria for HBsAg-positive mothers as those with the following attributes in the hospital information management system: (1) screened as HBsAg-positive by laboratory test; and (2) health care facility-delivery at a study site between April 2016 and March 2017. We excluded mothers who were: (1) ill at the time of the study contact; and/or (2) not contactable following requirements of study recruitment protocol. We defined inclusion criteria for HBV-exposed infants as: (1) born to HBsAg-positive mothers who met the inclusion criteria for the study; (2) born in health facilities of study sites between April 2016 and March 2017; (3) having completed the three-dose HBV vaccination schedule; (4) alive at time of study. We excluded infants who were: (1) ill at the time of the study contact; (2) not contactable following requirement of study recruitment protocol; and/or (3) guardian refusal for blood draw and testing procedure.

We applied the formula for the cross-sectional observational study to calculate the sample size:

$$
n=\frac{Z_{\alpha}^{2} \times p \times(1-p)}{(\delta p)^{2}}
$$

According to recent research in China, the reported HBsAg positivity rate among HBV-exposed infants after immunization intervention is $3-5 \%[9,10]$. We utilized a mean HBsAg positivity rate of $4 \%$. With an allowable deviation of $15 \%$, we calculated an approximate sample size of 4182 mother-child pairs.

First, we chose four provinces by stratified sampling. We stratified the 31 provinces, autonomous regions, and municipalities (not including Macau, Hong Kong, and Taiwan) in China served by the programme into quartiles of prevalence of HBsAg positivity among pregnant women in 2016. In each stratum, we used simple random sampling to select one province. We used convenience sampling to select between two to five counties/districts per province based on the highest estimated number of HBV-exposed infants to reach at least $n=1100$ in each province. In a total, we chose 13 counties/districts from Guangdong, Zhejiang, Shaanxi, and Hebei provinces as the research sites. In the study sites, we recruited all mother-child pairs identified through the hospital information system at all health care facilities offering delivery services.

Table 1 The intervention components, program outputs and outcomes, and associated indicators for the PMTCT of HBV component of the national programme on PMTCT of HIV, syphilis, and HBV in China

\begin{tabular}{|c|c|c|c|c|}
\hline Intervention component & Program output & Indicator & $\begin{array}{l}\text { Program } \\
\text { outcome }\end{array}$ & Indicator \\
\hline \multicolumn{5}{|l|}{ Pregnant Women } \\
\hline $\begin{array}{l}\text { HBV screening of pregnant } \\
\text { women attending } \\
\text { antenatal care }\end{array}$ & $\begin{array}{l}\text { Screening of pregnant } \\
\text { women for HBsAg }\end{array}$ & $\begin{array}{l}\text { Coverage of HBV screening for } \\
\text { pregnant women }\end{array}$ & & \\
\hline \multicolumn{5}{|l|}{ HBV-exposed Infants } \\
\hline $\begin{array}{l}\text { HBIG } 100 \text { IU within } 24 \mathrm{~h} \\
\text { of birth }\end{array}$ & $\begin{array}{l}\text { Timely birth-dose } \\
\text { (within } 24 \mathrm{~h} \text { of birth) of HBIG }\end{array}$ & $\begin{array}{l}\text { Timely HBIG coverage } \\
\text { (proportion of HBV-exposed } \\
\text { infants receiving timely } \\
\text { birth-dose of HBIG) }\end{array}$ & $\begin{array}{l}\text { Reduction in } \\
\text { HBV MTCT }\end{array}$ & $\begin{array}{l}\text { HBsAg positivity amongst } \\
\text { HBV-exposed infants in } \\
1 \text { year (MTCT rate) }\end{array}$ \\
\hline \multirow[t]{2}{*}{$\begin{array}{l}\text { Three-dose HBvacc } \\
\text { (provided by EPI) }\end{array}$} & $\begin{array}{l}\text { Timely HBvacc-BD } \\
\text { (within } 24 \mathrm{~h} \text { of birth) }\end{array}$ & $\begin{array}{l}\text { Timely HBvacc-BD coverage } \\
\text { (proportion of HBV-exposed } \\
\text { infants receiving timely HBvacc-BD) }\end{array}$ & $\begin{array}{l}\text { Sero-protection } \\
\text { from } \\
\text { immunization }\end{array}$ & $\begin{array}{l}\text { Anti-HBs positivity amongst } \\
\text { HBV-exposed infants within } \\
7-12 \text { months } \\
\text { (sero-protection rate) }\end{array}$ \\
\hline & $\begin{array}{l}\text { Completion of the second } \\
\text { and third dose HBvacc } \\
\text { (after } 1 \text { month and } 6 \text { month of birth) }\end{array}$ & $\begin{array}{l}\text { Proportion HBV-exposed } \\
\text { infants completing three-dose } \\
\text { HBvacc series }\end{array}$ & & \\
\hline
\end{tabular}

PMTCT prevention of mother-to-child transmission, $H B V$ hepatitis B virus, $H B s A g$ hepatitis B surface antigen, $H B I G$ hepatitis B immunoglobulin, $I U$ international unit, $H B v a c c-B D$ hepatitis $B$ vaccine birth dose, $M T C T$ mother-to-child transmission, $H B v a c c$ hepatitis $B$ vaccine, EPI expanded programme on immunization, anti-HBs hepatitis B surface antibody 


\section{Data collection and variables}

After obtaining informed consent and parental assent from the HBsAg-positive mothers, the study team interviewed mothers using a structured questionnaire to collect maternal demographics. The study team collected serological outcomes of HBV-exposed children by collecting blood samples and sending them for laboratory tests at designated maternal and children hospitals to detect HBsAg and hepatitis B surface antibody (antiHBs) markers by enzyme-linked immunosorbent assay (ELISA). The detection limits for anti-HBs and HBsAg were $10 \mathrm{IU} / \mathrm{L}$ and less than $1 \mathrm{IU} / \mathrm{ml}$ respectively. The study team reviewed the medical records of the motherchild pairs and immunization records of the children to extract data on maternal laboratory test results, mode of delivery and level of delivery hospitals; and child gestational age and birth weight and immunoprophylactic management through medical records.

We defined timely HBIG and HBvacc-BD coverage as the proportion of children who received HBIG and HBvacc-BD within $24 \mathrm{~h}$ of birth, respectively. We defined MTCT rate as the proportion of HBsAg positive and anti-HBs negative children among those born to HBV-positive mothers; and sero-protection rate (measured between 1 and 18 months from the third-dose HBvacc) as the proportion of $\mathrm{HBsAg}$ negative and anti-HBs positive children among those born to HBV-positive mothers. We defined short testing interval as less than 7 months between time of receiving the third-dose HBvacc and the time of the serological test study procedure. We defined low birth weight (LBW) as less than $2500 \mathrm{~g}$.

We classified HBvacc type into three groups: (1) $10 \mu \mathrm{g}$ yeast vaccine, derived from Saccharomyces cerevisiae, $10 \mu \mathrm{g} / 0.5 \mathrm{ml}$, produced by Beijing Tiantan Biological Products Co., Ltd., Beijing, China, or Shenzhen Kangtai Biological Products Co., Ltd., Shenzhen, China, and derived from Hansenula ploymorpha, $10 \mu \mathrm{g} / 0.5 \mathrm{ml}$, produced by Aimei Hissen Vaccine (Dalian) Co., Ltd., Dalian, China; (2) $20 \mu \mathrm{g}$ CHO vaccine, derived from Chinese hamster ovary cells $(\mathrm{CHO}), 20 \mu \mathrm{g} / 1 \mathrm{ml}$, produced by North China Pharmaceutical, Jintan biological products Co., Ltd., Shijiazhuang, China; 3) $10 \mu \mathrm{g}$ CHO vaccine, derived from $\mathrm{CHO}, 10 \mu \mathrm{g} / 0.5 \mathrm{ml}$, produced by North China Pharmaceutical, Jintan biological products Co., Ltd., Shijiazhuang, China.

\section{Statistical analysis}

Prior to data entry, we reviewed the questionnaire data and undertook checks for quality assurance. We double entered into and validated data using Epidata software (version 3.1, The EpiData Association, Odense, Denmark). We analysed the data using SPSS software (version 23.0, IBM Corp, Armonk, NY, USA). We presented categorized variables of demographic, immunization, birth history, and laboratory characteristics using frequencies and proportions, and continuous variables with normal distribution with mean and standard deviation $(S D)$. We summarized programme indicators using frequencies, proportions, and 95\% confidence intervals. We analysed the factors associated each of the MTCT and sero-protection rates using Pearson's chi-squared or Fisher's exact test, as appropriate. We entered the factors with a $P$ value of $<0.1$ into a binary logistic regression to build a final model for each of the MTCT and sero-protection rates. We consider a $P$ value of $<0.05$ as statistically significant.

\section{Results}

\section{Characteristics of the study population}

Through the recruiting process, we analysed data from 4112 mother-child pairs (Fig. 1). The average maternal age was $31 \pm 5$ years (range: $18-45$ years). The majority of mothers had a high middle school education or above (2730, 66\%), were from rural areas $(2818,69 \%)$, and had given birth at least once previously $(2380,58 \%)$. About $30 \%$ (1221) of mothers were HBeAg positive. In total, 26\% (1047) of mothers had an HBV DNA test during pregnancy documented, of which 291 resulted in HBV DNA level higher than 2000000 UI per milliliter. About 9.5\% (392) of mothers had taken antiviral drugs during the pregnancy. The average age of children was $14 \pm 4$ months (range: 7-22 months) (Table 2).

\section{Programme outcomes}

During 2016-2017, the programme achieved timely HBIG and HBvacc-BD coverage of 99\% (4070/4112) and 98\% (4045/4112) respectively. Children who received yeast vaccine at birth accounted for 88\% (3637) of the sample, and $86 \%$ (3538) were administered both HBvacc-BD and HBIG within $12 \mathrm{~h}$ of birth. The programme achieved an MTCT rate of $0.9 \%$ (0.6-1.1\%), with 35 children tested HBsAg positive, and a sero-protection rate of $96.8 \%$ (96.3-97.4\%), with 3981 children tested anti-HBs positive. Out of $35 \mathrm{HBsAg}$-positive children, 94\% were born to HBsAg- and HBeAg-positive mothers during this pregnancy. Of 4112 children, serological test results for $96(2.3 \%)$ were both HBsAg and anti-HBs negative (Table 2).

\section{Univariate and multivariate analysis on MTCT rate}

The timing of HBvacc-BD was associated with MTCT. For children administered the HBvacc-BD between 12 and $24 \mathrm{~h}$ in birth, the adjusted odds of MTCT was 1.9 times higher than that of children immunized within 12 $\mathrm{h}$ of birth $(2.4 \%$ vs $0.6 \%$, adjusted odds ratio $[\mathrm{aOR}]=2.9$, 95\% confidence interval $[C I]: 1.4-6.3, P=0.01)$. The MTCT rate was higher among children born to $\mathrm{HBeAg}$ positive mothers than those born to $\mathrm{HBeAg}$ negative 


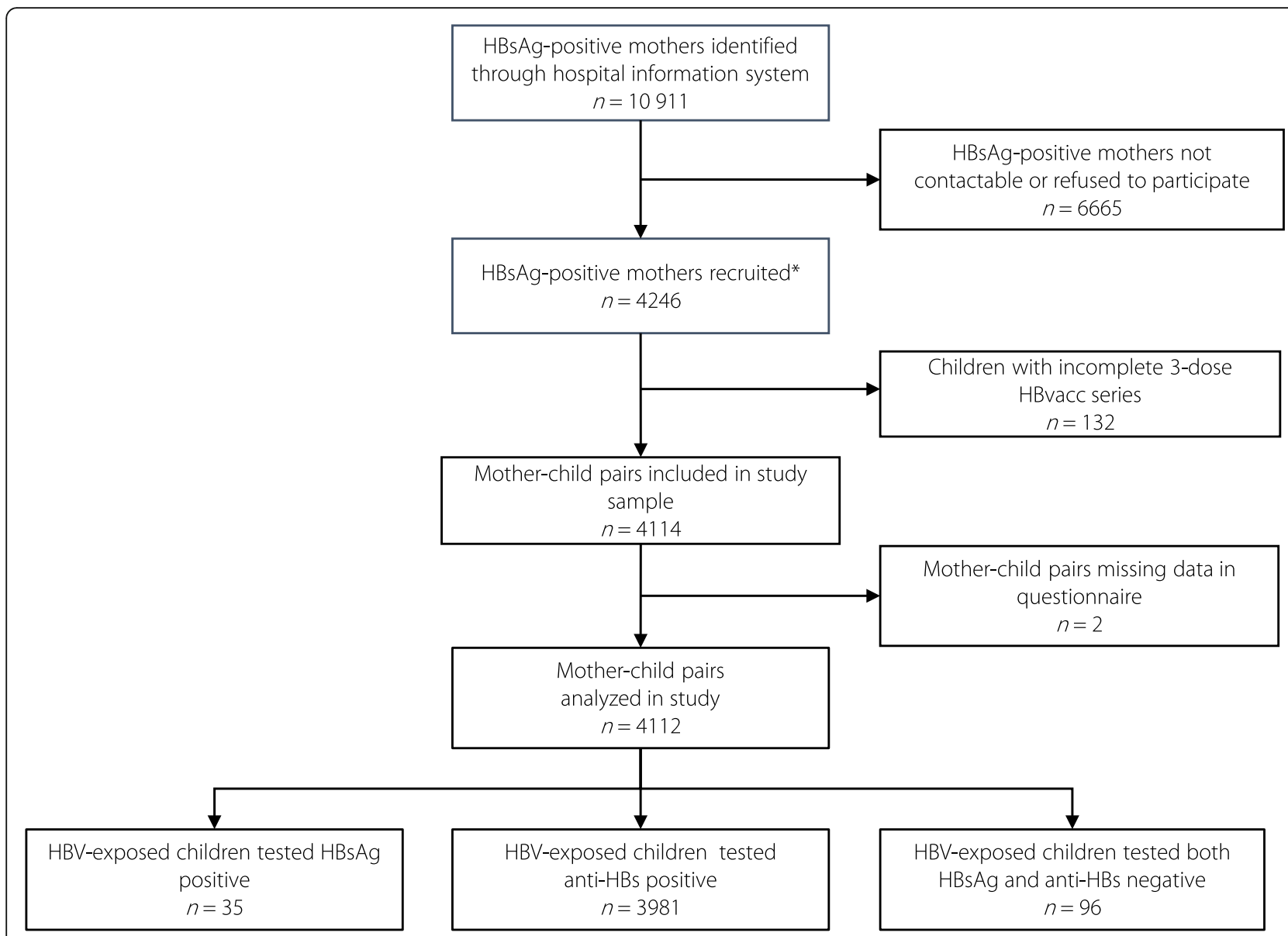

Fig. 1 The recruitment process of mother-infant pairs in the study of outcomes of the national programme on PMTCT of HBV in China, 2016-2017. PMTCT: Prevention of mother-to-child transmission; HBV: Hepatitis B virus; HBsAg: Hepatitis B surface antigen; HBeAg: Hepatitis B e antigen; anti-HBs: Hepatitis B surface antibody; HBvacc: Hepatitis B vaccine; 3-dose HBvacc series: First dose within 24 hours of birth, second dose after 1 month, third dose after 6 months, ${ }^{*}$ Children had HBV serological marker test

mothers $(2.7 \%$ vs $0.04 \%$, aOR $=79.1,95 \%$ CI: $10.8-580.2$, $P<0.001)$. We found a higher MTCT rate among children delivered in hospitals at county level or below than in those delivered at prefectural hospitals or above $(1.1 \%$ vs $0.4 \%$, aOR $=3.3,95 \% C I$ : $1.3-8.0, P=0.01)$. We found no significant association between MTCT and maternal age, educational level, parity, or antiviral treatment during this pregnancy, or with the child's gender, gestational age, HBIG administration, or birth weight (Table 3).

Univariate and multivariate analysis on sero-protection rate We found a lower sero-protection rate among children with LWB than those born over $2500 \mathrm{~g}$ (93\% vs $97 \%$, $\mathrm{aOR}=0.4,95 \% C I: 0.2-0.8, P=0.01)$. Children with a shorter testing interval showed a higher sero-protection rate than those with a longer testing interval ( $98 \%$ vs $96 \%$, $\mathrm{aOR}=2.2,95 \% C I: 1.5-3.4, P<0.001)$. The proportions of anti-HBs negative children among HBV-exposed children born to $\mathrm{HBeAg}$ positive and $\mathrm{HBeAg}$ negative mothers were $2.2 \%(59 / 2740)$ and $5.4 \%(66 / 1221)$ respectively $(P<0.001)$ (Table 4).

\section{Discussion}

We found strong programme performance with regards to timely HBIG and HBvacc-BD coverage and a relatively low MTCT rate and high sero-protection rate compared with previous research conducted in China for 2006-2014 [6, 9, 10]. We found most HBV-infected children were born to mothers with both HBsAg and HBeAg positivity during the pregnancy. Our results show progress towards rates comparable to those reported by the United States Perinatal Hepatitis B Prevention Programs for 2007-2013 (1.1\%) [17]. Our finding of strong PMTCT performance among children with HBIG is consistent with current knowledge about efficiency and effectiveness of PMTCT of HBV by combined HBIG and three-dose HBvacc [18, 19].

The 2018-2030 WHO Western Pacific Regional framework for triple elimination of MTCT of HIV, 
Table 2 Characteristics of HBsAg-positive mothers and their HBV-exposed children in four provinces, China 2016-2017

\begin{tabular}{lll}
\hline Characteristics & $N$ & $\%$ \\
\hline Total & 4112 & 100.0
\end{tabular}

Province

$\begin{array}{lll}\text { Guangdong } & 1297 & 31.5 \\ \text { Hebei } & 920 & 22.4 \\ \text { Shaanxi } & 718 & 17.5 \\ \text { Zhejiang } & 1177 & 28.6 \\ \text { Maternal age (years) } & & \\ \text { 18-24 } & 280 & 6.8 \\ \text { 25-34 } & 2992 & 72.8 \\ \text { 35-45 } & 840 & 20.4 \\ \text { Maternal educational level } & & \\ \text { Junior middle school and below } & 1382 & 33.6 \\ \text { High middle school and above } & 2730 & 66.4 \\ \text { Maternal residence rural/urban } & & \\ \text { Rural } & 2818 & 68.5 \\ \text { Urban } & 1294 & 31.5 \\ \text { Maternal Parity } & & \\ \text { 1 } & 1732 & 42.1 \\ >1 & 2380 & 57.9\end{array}$

Maternal HBeAg status during this pregnancy

Positive 1221

Negative 2740

Unknown

Maternal HBV DNA during this pregnancy (IU/ml)

$$
<100
$$

$100-2000000$

$>2000000$

Unknown

Maternal antiviral treatment during this pregnancy

$$
\text { Yes }
$$

No

\section{2}

3720

Level of delivery hospital

County level and below

Prefectural and above

Mode of delivery

$$
\text { Vaginal delivery }
$$

Caesarean section

Child age (months)

$\begin{array}{lll}7-12 & 1626 & 63.1 \\ 13-22 & 2486 & 36.9 \\ \text { Child gender } & & \\ \text { Male } & 2185 & 53.1 \\ & 1927 & 46.9\end{array}$

Female
Table 2 Characteristics of HBsAg-positive mothers and their HBV-exposed children in four provinces, China 2016-2017 (Continued)

\begin{tabular}{lll}
\hline Characteristics & $N$ & $\%$ \\
\hline Gestational age (weeks) & & \\
$\quad<37$ & 236 & 5.7 \\
$37-43$ & 3876 & 94.3 \\
Child birth weight (g) & \\
$\quad<2500$ (LBW) & 131 & 3.2 \\
$2500-5400$ & 3981 & 96.8 \\
Interval between birth and HBvacc-BD (hours) & \\
$<12$ & 3579 & 87.0 \\
$12-24$ & 466 & 11.3 \\
$>24$ & 67 & 1.7 \\
Type of HBvacc-BD & & \\
$10 \mu g$ yeast vaccine & 3637 & 88.5 \\
$20 \mu g$ CHO vaccine & 285 & 6.9 \\
$10 \mu g$ CHO vaccine & 190 & 4.6 \\
Interval between birth and HBIG dose (hours) & \\
$<12$ & 3888 & 94.6 \\
$12-24$ & 182 & 4.4 \\
$>24$ & 22 & 0.5 \\
No & 20 & 0.5 \\
& & \\
& &
\end{tabular}

Received both HBvacc birth dose and HBIG within $12 \mathrm{~h}$ of birth

$\begin{array}{lll}\text { Yes } & 3538 & 86.0 \\ \text { No } & 574 & 14.0\end{array}$

Interval between third dose HBvacc and HBV serological test (months)

$$
\begin{array}{lll}
<7 & 1666 & 40.5 \\
7-18 & 2446 & 59.5
\end{array}
$$

$H B s A g$ hepatitis $B$ surface antigen, $H B V$ hepatitis $B$ virus, $H B e A g$ hepatitis $B$ e antigen, $H B$ vacc hepatitis $B$ vaccine, $H B v a c c-B D$ hepatitis $B$ vaccine birth dose, $H B I G$ hepatitis $B$ immunoglobulin, $L B W$ low birth weight, $C H O$ Chinese hamster ovary, IU international unit

HBV and syphilis in Asia and the Pacific set a regional target of prevalence of $\mathrm{HBsAg}$ among children of no more than $0.1 \%$ by 2030 [3]. In order to achieve the elimination goal in China, with an estimated 6\% HBsAg prevalence among pregnant women, the MTCT rate needs to remain lower than 2\% [12]. Our findings imply the national PMTCT programme for HBV is on track to achieve the elimination target by 2030 if efforts continue to sustain the progress achieved thus far and to tackle barriers for timely service access.

We demonstrated that the timing of HBvacc-BD was associated with risk of infection in children, with lower MTCT rates among children administered the HBvacc within $12 \mathrm{~h}$ of birth. Our findings are consistent with WHO recommendation that infants should receive HBvacc-BD as soon as possible from the time of and within $24 \mathrm{~h}$ of birth. The American Academy of Pediatrics 
Table 3 Univariate and multivariate analysis of factors associated with HBV infection among children born to HBsAg-positive mothers in four provinces, China 2016-2017

\begin{tabular}{|c|c|c|c|c|c|c|}
\hline \multirow[t]{2}{*}{ Characteristics } & \multirow{2}{*}{$\begin{array}{l}\text { Number of } \\
\text { observations }\end{array}$} & \multirow{2}{*}{$\begin{array}{l}\text { HBsAg Positive } \\
N(\%)\end{array}$} & \multicolumn{2}{|l|}{ Univariate analysis } & \multicolumn{2}{|c|}{ Multivariable analysis } \\
\hline & & & $O R(95 \% C l)$ & $P$-value & $\mathrm{aOR}(95 \% \mathrm{Cl})$ & $P$-value \\
\hline \multicolumn{7}{|l|}{ Maternal age (years) } \\
\hline $18-24$ & 280 & $3(1.1)$ & $2.3(0.5-10.2)$ & $0.2^{\#}$ & & \\
\hline $25-34$ & 2992 & 28(0.9) & $2.0(0.7-5.6)$ & & & \\
\hline $35-45$ & 840 & $4(0.5)$ & 1 & & & \\
\hline \multicolumn{7}{|l|}{ Maternal educational level } \\
\hline Junior middle school and below & 1382 & $12(0.9)$ & $1.0(0.5-2.1)$ & 0.9 & & \\
\hline High middle school and above & 2730 & 23(0.8) & 1 & & & \\
\hline \multicolumn{7}{|l|}{ Maternal residence rural / urban } \\
\hline Rural & 2818 & $28(1.0)$ & $1.8(0.8-4.2)$ & 0.1 & & \\
\hline Urban & 1294 & $7(0.5)$ & 1 & & & \\
\hline \multicolumn{7}{|l|}{ Maternal parity } \\
\hline 1 & 1732 & $18(1.0)$ & $1.5(0.8-2.8)$ & 1.3 & & \\
\hline$>1$ & 2380 & $17(0.7)$ & 1 & & & \\
\hline \multicolumn{7}{|c|}{ Maternal HBeAg status during this pregnancy } \\
\hline Positive & 1221 & $33(2.7)$ & $76.1(10.4-556.9)$ & $<0.001^{\#}$ & $79.1(10.8-580.2)$ & $<0.001$ \\
\hline Negative & 2740 & $1(0.04)$ & 1 & & 1 & \\
\hline Unknown & 151 & $1(0.7)$ & $18.3(1.1-293.4)$ & & $16.7(1.0-269.6)$ & 0.05 \\
\hline \multicolumn{7}{|c|}{ Maternal antiviral treatment during this pregnancy } \\
\hline Yes & 392 & $1(0.3)$ & $0.3(0.0-2.0)$ & $0.25^{*}$ & & \\
\hline No & 3720 & $34(0.9)$ & 1 & & & \\
\hline \multicolumn{7}{|l|}{ Level of delivery hospital } \\
\hline County level and below & 2594 & 29(1.1) & $2.8(1.2-6.9)$ & 0.02 & $3.3(1.3-8.0)$ & 0.01 \\
\hline Prefectural and above & 1518 & $6(0.4)$ & 1 & & 1 & \\
\hline \multicolumn{7}{|l|}{ Mode of delivery } \\
\hline Vaginal delivery & 2349 & $23(1.0)$ & $1.4(0.72-2.9)$ & 0.3 & & \\
\hline Caesarean section & 1763 & $12(0.7)$ & 1 & & & \\
\hline \multicolumn{7}{|l|}{ Child gender } \\
\hline Male & 2185 & $17(0.8)$ & $0.8(0.4-1.6)$ & 0.6 & & \\
\hline Female & 1927 & $18(0.9)$ & 1 & & & \\
\hline \multicolumn{7}{|l|}{ Gestational age (weeks) } \\
\hline$<37$ & 236 & $3(1.3)$ & $1.5(0.5-5.1)$ & $0.5^{*}$ & & \\
\hline $37-43$ & 3876 & $32(0.8)$ & & & & \\
\hline \multicolumn{7}{|l|}{ Child birth weight (g) } \\
\hline$<2500($ LBW $)$ & 131 & $3(2.3)$ & $2.9(0.9-9.6)$ & $0.09^{*}$ & $2.7(0.8-9.7)$ & 0.1 \\
\hline $2500-5400$ & 3981 & $32(0.8)$ & 1 & & 1 & \\
\hline \multicolumn{7}{|l|}{ Type of HBvacc-BD } \\
\hline $10 \mu \mathrm{g}$ yeast vaccine & 3637 & $29(0.8)$ & $0.8(0.2-3.2)$ & 0.5 & & \\
\hline $20 \mu \mathrm{g}$ CHO vaccine & 285 & $4(1.4)$ & $1.3(0.2-7.4)$ & & & \\
\hline $10 \mu \mathrm{g} \mathrm{CHO}$ vaccine & 190 & $2(1.1)$ & 1 & & & \\
\hline \multicolumn{7}{|c|}{ Interval between birth and HBvac-BD (hours) } \\
\hline Within 12 & 3579 & 23(0.6) & 1 & $0.001^{\#}$ & 1 & \\
\hline $12-24$ & 466 & $11(2.4)$ & $3.7(1.8-7.7)$ & & $2.9(1.4-6.3)$ & 0.01 \\
\hline
\end{tabular}


Table 3 Univariate and multivariate analysis of factors associated with HBV infection among children born to HBsAg-positive mothers in four provinces, China 2016-2017 (Continued)

\begin{tabular}{|c|c|c|c|c|c|c|}
\hline \multirow[t]{2}{*}{ Characteristics } & \multirow{2}{*}{$\begin{array}{l}\text { Number of } \\
\text { observations }\end{array}$} & \multirow{2}{*}{$\begin{array}{l}\text { HBsAg Positive } \\
N(\%)\end{array}$} & \multicolumn{2}{|c|}{ Univariate analysis } & \multicolumn{2}{|c|}{ Multivariable analysis } \\
\hline & & & $O R(95 \% C l)$ & $P$-value & $\mathrm{aOR}(95 \% \mathrm{Cl})$ & $P$-value \\
\hline$>24$ & 67 & $1(1.5)$ & $2.4(0.3-17.6)$ & & $2.1(0.3-17.7)$ & 0.5 \\
\hline \multicolumn{7}{|c|}{ Administered $\mathrm{HBIG}$} \\
\hline Yes & 4092 & $35(0.9)$ & $0.99(0.98-0.99)$ & $1.0^{*}$ & & \\
\hline No & 20 & $0(0.0)$ & 1 & & & \\
\hline \multicolumn{7}{|c|}{ Interval between 3rd dose HBvacc and HBV serological marker test (months) } \\
\hline$<7$ & 1666 & $12(0.7)$ & $0.8(0.4-1.5)$ & 0.5 & & \\
\hline $7-18$ & 2446 & $23(0.9)$ & 1 & & & \\
\hline
\end{tabular}

$H B V$ hepatitis $B$ virus, $H B s A g$ hepatitis $B$ surface antigen, $H B e A g$ HBV e antigen, $H B v a c c$ hepatitis $B$ vaccine, $H B v a c c-B D$ hepatitis $B$ vaccine birth dose, $H B I G$ hepatitis $B$ immunoglobulin, $L B W$ low birth weight, $C H O$ Chinese hamster ovary, \#: trend, *: Fisher's exact test, $O R$ odds ratio, aOR adjusted odds ratio, factors significant at $P<0.1$ in univariate analysis entered into the regression model)

endorses the recommendation to administer both HBvacc and HBIG within $12 \mathrm{~h}$ of birth, regardless of any maternal antenatal treatment with antiviral medication [20]. Our results provide additional evidence to verify the importance of timely HBvacc-BD and demonstrate a need to update the current national guidelines recommendation to a requirement for vaccination within $12 \mathrm{~h}$ of birth [8].

Our findings confirm the high risk of MTCT among children born to HBsAg- and HBeAg-positive mothers. $\mathrm{HBeAg}$ positivity is linked with higher levels of $\mathrm{HBV}$ replication and associated with intrauterine transmission of HBV [21]. The provision of antiviral prophylaxis has been reported as an additional protective measure to HBIG and HBvacc for children born to mothers with high HBV DNA level [22-24]. Our findings may be consistent with previous studies that showed a reduced MTCT risk associated with antiviral treatment for pregnant women with therapeutic indications [22-24]. However, the proportion of the pregnant women with $\mathrm{HBV}$ DNA test results who also received antiviral treatment in our study was fewer than $8 \%$, possibly hindering the interpretation of these results.

We found the level of hospital associated with MTCT risk. We consider reflective of variances in the management of vaccination procedures and understanding of hepatitis $\mathrm{B}$ vaccination contraindications among health care providers at different levels of hospitals [25, 26]. The results indicate the need for further studies on quality of care with regards to HBIG and HBvacc immunization and their association with facility-level factors.

We found maternal HBeAg positivity was associated with lower sero-protection rates. This implies that children born to mothers who were both HBsAg and HBeAg positive are at a higher risk for either perinatal HBV infection or failure to obtain sero-protection from immunoprophylaxis. Children without sero-protection from anti-HBs may be at higher risk of infection from their HBsAg-positive mothers or other family members [27]. We found a small number of mothers with an unknown HBeAg status, despite screening being required by the national action plan [13], and ever few with a recorded HBV DNA test during pregnancy. Hence, it is important to standardize the provision of supplementary tests to HBsAg-positive pregnant women to identify those with $\mathrm{HBeAg}$-positivity or high HBV DNA levels to provide appropriate medical care and follow-up services to this groups of mothers and their children.

Our findings of significantly lower sero-protection among children with LBW may be explained by: lower responsiveness of LBW infants to HBvacc [28] and/or delayed administration of HBvacc-BD ( $>24 \mathrm{~h}$ of birth) for preterm birth or LBW $[29,30]$. WHO recommends that infants born less than $2000 \mathrm{~g}$ should be given HBvacc-BD, but that the dose should not count as part of the primary three-dose HBvacc [31]. The US guidelines recommend that infants of all birth weights born to HBsAg-positive mothers receive both the HBvacc and HBIG within $12 \mathrm{~h}$ of birth [20]. In China, the $2016 \mathrm{Na}$ tional EPI guidelines similarly require $\mathrm{HBvacc-BD}$ regardless of birth weight for HBV-exposed infants, followed by the three-dose HBvacc series [8]. Our findings may point to the need for future studies on adherence to the guidelines for the timely provision of Hepatitis $B$ vaccination for low birth weight infants born to HBsAg-positive mothers among healthcare providers.

\section{Limitations}

Our research has several potential limitations. First, due to resource constraints, we undertook data collection over a limited period of time. As a result, about $60 \%$ of the HBVexposed children received HBV serologic testing over seven months after their third dose of HBvacc, as opposed to the recommended window of one to two months during which anti-HBs levels are at their highest $[9,32]$. In the absence of more stringent inclusion criteria, we may have estimated a lower sero-protection rate. Second, as we 
Table 4 Univariate and multivariate analysis of factors associated with sero-protection among children born to HBsAg-positive mothers in four provinces, China 2016-2017

\begin{tabular}{|c|c|c|c|c|c|c|}
\hline \multirow[t]{2}{*}{ Characteristics } & \multirow{2}{*}{$\begin{array}{l}\text { No. of } \\
\text { observations }\end{array}$} & \multirow{2}{*}{$\begin{array}{l}\text { Anti-HBs Positive } \\
n(\%)\end{array}$} & \multicolumn{2}{|c|}{ Univariate analysis } & \multicolumn{2}{|c|}{ Multivariable analysis } \\
\hline & & & OR $(95 \% C l)$ & $P$-value & $\mathrm{aOR}(95 \% \mathrm{Cl})$ & $P$-value \\
\hline \multicolumn{7}{|l|}{ Maternal age (years) } \\
\hline $18-24$ & 280 & $272(97.1)$ & $1.0(0.4-2.2)$ & 0.8 & & \\
\hline $25-34$ & 2992 & $2893(96.7)$ & $0.8(0.5-1.3)$ & & & \\
\hline $35-45$ & 840 & $816(97.1)$ & & & & \\
\hline \multicolumn{7}{|l|}{ Maternal educational level } \\
\hline Junior middle school or below & 1382 & $1341(97.0)$ & $1.1(0.8-1.6)$ & 0.6 & & \\
\hline High Middle school or above & 2730 & $2640(96.7)$ & 1 & & & \\
\hline \multicolumn{7}{|l|}{ Maternal residence rural / urban } \\
\hline Rural & 2818 & $2731(96.9)$ & $1.1(0.8-1.6)$ & 0.6 & & \\
\hline Urban & 1294 & 1250 (96.6) & 1 & & & \\
\hline \multicolumn{7}{|l|}{ Maternal parity } \\
\hline 1 & 1732 & 1679 (96.9) & $1.1(0.8-1.5)$ & 0.7 & & \\
\hline$>1$ & 2380 & $2302(96.7)$ & 1 & & & \\
\hline \multicolumn{7}{|c|}{ Maternal HBeAg status during this pregnancy } \\
\hline Positive & 1221 & $1155(94.6)$ & $0.4(0.3-0.6)$ & $<0.001^{\#}$ & $0.4(0.3-0.6)$ & $<0.001$ \\
\hline Negative & 2740 & $2681(97.8)$ & 1 & & 1 & \\
\hline Unknown & 151 & $145(96.0)$ & $0.5(0.2-1.3)$ & & $0.6(0.2-1.3)$ & 0.2 \\
\hline \multicolumn{7}{|c|}{ Maternal antiviral treatment during this pregnancy } \\
\hline Yes & 392 & $377(96.2)$ & $0.8(0.5-1.4)$ & 0.5 & & \\
\hline No & 3720 & $3604(96.9)$ & 1 & & & \\
\hline \multicolumn{7}{|l|}{ Level of delivery hospital } \\
\hline Prefectural and above & 1518 & $1463(96.4)$ & $0.8(0.6-1.1)$ & 0.2 & & \\
\hline County level and below & 2594 & $2518(97.1)$ & 1 & & & \\
\hline \multicolumn{7}{|l|}{ Mode of delivery } \\
\hline Vaginal delivery & 2349 & $2271(96.7)$ & $0.9(0.6-1.3)$ & 0.6 & & \\
\hline Caesarean section & 1763 & $1710(97.0)$ & 1 & & & \\
\hline \multicolumn{7}{|l|}{ Child gender } \\
\hline Male & 2185 & $2118(96.9)$ & $1.1(0.8-1.5)$ & 0.6 & & \\
\hline Female & 1927 & $1863(96.7)$ & 1 & & & \\
\hline \multicolumn{7}{|l|}{ Gestational age (weeks) } \\
\hline$<37$ & 236 & $225(95.3)$ & $0.7(0.3-1.2)$ & 0.2 & & \\
\hline $37-43$ & 3876 & $3756(96.9)$ & 1 & & & \\
\hline \multicolumn{7}{|l|}{ Child birth weight (g) } \\
\hline$<2500$ & 131 & $122(93.1)$ & $0.4(0.2-0.9)$ & $0.02^{*}$ & $0.4(0.2-0.8)$ & 0.01 \\
\hline $2500-5400$ & 3981 & 3859 (96.9) & 1 & & 1 & \\
\hline \multicolumn{7}{|l|}{ Type of HBvacc-BD } \\
\hline $10 \mu g$ yeast vaccine & 3637 & $3520(96.8)$ & $1.3(0.6-2.7)$ & 0.4 & & \\
\hline $20 \mu \mathrm{g}$ CHO vaccine & 285 & $279(97.9)$ & $2.0(0.7-6.0)$ & & & \\
\hline $10 \mu \mathrm{g}$ CHO vaccine & 190 & $182(95.8)$ & 1 & & & \\
\hline \multicolumn{7}{|c|}{ Interval between birth and HBvacc-BD (hours) } \\
\hline Within 12 & 3579 & $3467(96.9)$ & 1 & $0.5^{*}$ & & \\
\hline $12-24$ & 466 & $450(96.6)$ & $0.9(0.5-1.5)$ & & & \\
\hline
\end{tabular}


Table 4 Univariate and multivariate analysis of factors associated with sero-protection among children born to HBsAg-positive mothers in four provinces, China 2016-2017 (Continued)

\begin{tabular}{|c|c|c|c|c|c|c|}
\hline \multirow[t]{2}{*}{ Characteristics } & \multirow{2}{*}{$\begin{array}{l}\text { No. of } \\
\text { observations }\end{array}$} & \multirow{2}{*}{$\begin{array}{l}\text { Anti-HBs Positive } \\
n(\%)\end{array}$} & \multicolumn{2}{|c|}{ Univariate analysis } & \multicolumn{2}{|c|}{ Multivariable analysis } \\
\hline & & & $O R(95 \% C l)$ & $P$-value & $\mathrm{aOR}(95 \% \mathrm{Cl})$ & $P$-value \\
\hline$>24$ & 67 & $64(95.5)$ & $0.7(0.2-2.2)$ & & & \\
\hline \multicolumn{7}{|c|}{ Administered $\mathrm{HBIG}$} \\
\hline Yes & 4092 & $3961(96.8)$ & $1.0(0.96-0.97)$ & $1.0^{*}$ & & \\
\hline No & 20 & $20(100.0)$ & 1 & & & \\
\hline \multicolumn{7}{|c|}{ Interval between 3rd dose HBvacc and HBV serological marker test (months) } \\
\hline$<7$ & 1666 & $1635(98.1)$ & $2.2(1.5-3.4)$ & $<0.001$ & $2.2(1.5-3.4)$ & $<0.001$ \\
\hline $7-18$ & 2446 & 2346 (95.9) & 1 & & 1 & \\
\hline
\end{tabular}

$H B V$ hepatitis $B$ virus, $H B s A g$ hepatitis $B$ surface antigen, anti-HBs hepatitis B surface antibody, $H B v a c c$ hepatitis $B$ vaccine, $H B v a c c-B D$ hepatitis $B$ vaccine birth dose, $H B I G$ hepatitis $B$ immunoglobulin, $L B W$ low birth weight, $C H O$ Chinese hamster ovary, \#: trend, *: Fisher's exact test, the factors significant at $P<0.1$ in univariate analysis entered into the regression model

utilized convenience sampling, our study sample does not allow for generalization of results nation-wide. Therefore, our results may reflect selection bias for areas where the programme has been more effectively implemented. Hence, further studies are needed to understand the MTCT and sero-protection rates in other geographical regions of China, particularly in areas with poor programme performance. Third, insufficient availability of HBV DNA test results for mothers limited our ability to investigate any association between and HBV DNA levels and MTCT and sero-protection rates. However, as the majority of our data were extracted from hospital records or information systems, we were able to reduce potential recall bias.

\section{Conclusions}

This study found an MTCT rate among children born to HBsAg-positive mothers lower than $2 \%$, which reflects the effectiveness and efficiency of the national programme. These results are encouraging with respect to the 2030 elimination goal [3]. Hence, we recommend continuing to strengthen current PMTCT intervention strategies to ensure immunoprophylaxis including timely HBvacc series and HBIG. It is crucial to emphasize early HBvacc-BD (within $12 \mathrm{~h}$ at birth, as soon as possible) for HBV-exposed infants, which may be achieved by an amendment to the current EPI guidelines. In the context of high coverage of post-exposure immunoprophylaxis interventions, infants born to $\mathrm{HBeAg}$-positive mothers still face a higher risk of HBV infection and a lack of sero-protection. In order to eliminate HBV MTCT, it is necessary to identify all $\mathrm{HBeAg-positive} \mathrm{mothers} \mathrm{during} \mathrm{pregnancy} \mathrm{through} \mathrm{pro-}$ viding all $\mathrm{HBsAg}$ positive pregnant women with $\mathrm{HBeAg}$ test and providing identified mother-child pairs with appropriate medical care and follow-up. Finally, we recommend future studies on the implementation of HBvacc$\mathrm{BD}$ among preterm or LBW HBV-exposed infants as well as studies on health facility-level factors and their association to MTCT and sero-protection rates.

\section{Additional file}

Additional file 1: Multilingual abstracts in the five official working languages of the United Nations. (PDF $228 \mathrm{~kb}$ )

\section{Abbreviations}

anti-HBs: HBV surface antibody; aOR: Adjusted odds ratio; CDC: Centres for Diseases Control and Prevention; CHO: Chinese hamster ovary cells; Cl: Confidence interval; ELISA: Enzyme linked immunosorbent assay; EPI: Expanded Programme on Immunization; HBeAg: Hepatitis B e antigen; HBIG: Hepatitis B immunoglobulin; HBsAg: Hepatitis B surface antigen; HBV: Hepatitis B virus; HBvacc: Hepatitis B vaccine; HBvacc-BD: Hepatitis B vaccine birth dose; HIV: Human immunodeficiency virus; IU: International unit; LBW: Low birth weight; MTCT: Mother-to-child transmission; OR: Odds ratio; PMTCT: Prevention of mother-to-child transmission; SD: Standard deviation; US: The United States; WHO: World Health Organization

\section{Acknowledgements}

We would like to express our thanks to the Hebei, Zhejiang, Guangdong and Shaanxi provincial, prefecture and county staff who contributed to the field work as well as all participants. This research was conducted through the Structured Operational Research and Training Initiative (SORT-IT), a global partnership coordinated by the Special Programme for Research and Training in Tropical Diseases at the World Health Organization (WHO/TDR). The training model is based on a course developed jointly by the International Union Against Tuberculosis and Lung Disease (The Union) and Médecins Sans Frontières (MSF). The specific SORT-IT programme which resulted in this publication was implemented by: Médecins Sans Frontières, Brussels Operational Centre, Luxembourg and the China Centre for Disease Control \& Prevention. Mentorship and the coordination/facilitation of this SORT-IT workshop were provided through the University of Washington, Department of Global Health, USA; AMPATH, Eldoret, Kenya; Sustainable Health Systems, Sierra Leone; Universidad Pontificia Bolivariana, Columbia; Global AIDS Interfaith Alliance, USA; Centre for Operational Research, The Union, Paris, France; and the China Centre for Disease Control \& Prevention.

\section{Authors' contributions}

QYP, SM, SY, WXY, DLX, WQ, HXN, YYN, WAL and JX conceived and designed the study. QYP, SM, SY, LZ, LYL WAL conducted the data collection and analysis. QYP, KH and ZGM interpreted the results and wrote the first and subsequent drafts of the paper. All authors read and approved the final paper.

\section{Funding}

The study was funded by UNICEF China (501 Health, Nutrition and Wash, Activity No. 1.3.1.3\&1.3.2.4). Funding for the costs of publication in an open-access, peer-reviewed journal was supported by the SORT IT programme (WHO/TDR).

Availability of data and materials

Data is available upon reasonable request to the corresponding author. 


\section{Ethics approval and consent to participate}

This study was reviewed and approved by the China Centre for Disease Control and Prevention Ethics Review board (No. 201819) and the Institutional Review Board of the National Centre for Women and Children's Health, China CDC (No. FY2017-013). All participants provided informed consent/parental assent to participate in this study.

\section{Competing interests}

The authors declare that they have no competing interests.

\section{Author details}

${ }^{1}$ National Centre for Women and Children's Health, China CDC, Beijing, China. ${ }^{2}$ Community Health Service Centre, Dingzigu Street, Hongqiao District, Tianjin, China. ${ }^{3}$ Chengdu University of Traditional Chinese Medicine, Chengdu, China. ${ }^{4}$ Sustainable Health Systems, Freetown, Sierra Leone. ${ }^{5}$ Institute of Immunization, China CDC, Beijing, China. ${ }^{6}$ UNICEF China, Beijing, China.

Received: 16 January 2019 Accepted: 9 July 2019

Published online: 05 August 2019

\section{References}

1. World Health Organization. Global hepatitis report, 2017. Available from: https://apps.who.int/iris/bitstream/handle/10665/255016/9789241565455eng.pdf?sequence=1. Accessed 18 Dec 2018 .

2. World Health Organization. Global health sector strategy on viral hepatitis 2016-2021. Available from: https://apps.who.int/iris/bitstream/handle/1 0665/246177/WHO-HIV-2016.06-eng.pdf;jsessionid=EDEC6E554B6B9B033 ADAA8F4C58B66AB? sequence=1. Accessed 18 Dec 2018

3. World Health Organization Regional Office for the Western Pacific Region Regional framework for the triple elimination of mother-to-child transmission of HIV, hepatitis B and syphilis in Asia and the Pacific 2018-2030. Available from: http://iris.wpro.who.int/bitstream/handle/10665.1/14193/9789290618553eng.pdf. Accessed 18 Nov 2018

4. World Health Organization Regional Office for the Western Pacific Region Regional action plan for viral hepatitis in the Western Pacific 2016-2020. Available from: https://iris.wpro.who.int/bitstream/handle/10665.1/13141/ 97892906177617_eng.pdf. Accessed 18 Apr 2019.

5. Liang XF, Bi SL, Yang WZ, Wang LD, Cui G, Cui FQ, et al. Epidemiological serosurvey of hepatitis B in China - declining HBV prevalence due to hepatitis B vaccination. Vaccine. 2009;27(47):6550-7.

6. Zou H, Chen Y, Duan Z, Zhang H, Pan C. Virologic factors associated with failure to passive-active immunoprophylaxis in infants born to $\mathrm{HBsAg}$ positive mothers. J Viral Hepat. 2012;19(2):e18-25.

7. Cui FQ, Shen LP, Li L, Wang HQ, Wang FZ, Bi SL, et al. Prevention of chronic hepatitis B after 3 decades of escalating vaccination policy, China. Emerg Infect Dis. 2017;23(5):765-72.

8. National Health and Family Planning Commission of the people's Republic of China. Immunization procedure and instruction for children immunization of national immunization program. Available from: http:// www.nhc.gov.cn/ewebeditor/uploadfile/2016/12/20161229154305808.docx. Accessed 19 Dec 2018 (in Chinese).

9. Wang FZ, Zhang GM, Zheng H, Miao N, Shen LP, Wang F, et al. Postvaccination serologic testing of infants born to hepatitis $B$ surface antigen positive mothers in 4 provinces of China. Vaccine. 2017;35(33): 4229-35.

10. Wang FZ, Zheng $H$, Zhang GM, Ding ZP, Li FJ, Zhong G, et al. Effectiveness of prevention of mother-to-child transmission practice in three provinces of southern China. Hum Vaccin Immunother. 2015;11(8):2061-7.

11. Cui FQ, Woodring J, Chan P, Xu FJ. Considerations of antiviral treatment to interrupt mother-to-child transmission of hepatitis B virus in China. Int J Epidemiol. 2018;47(5):1529-37.

12. Wang AL, Qiao YP, Wang LH, Fang LW, Wang F, Jin $X$, et al. Integrated prevention of mother-to-child transmission for human immunodeficiency virus, syphilis and hepatitis B virus in China. Bull World Health Organ. 2015; 93(1):52-6.

13. National Health and Family Planning Commission of the people's Republic of China. Action plan to prevent mother-to-child transmission of HIV, syphilis and Hepatitis B virus. 2015 version. Available from: http://www.nhc. gov.cn/ewebeditor/uploadfile/2015/06/20150615151817186.docx. Accessed 10 Jan 2019 (in Chinese).

14. World Health Organization Regional Office for the Western Pacific. Report of the regional director: the work of WHO in the Western Pacific Region 1 July 2017-30 June 2018. Available from: http://iris.wpro.who.int/bitstream/ handle/10665.1/14212/WPR-RC069-02-RDrep-2018-en.pdf. Access 19 Mar 2019.

15. von Elm E, Altman DG, Egger M, Pocock SJ, Gøtzsche PC, Vandenbroucke JP. Strengthening the reporting of observational studies in epidemiology (stroBE) statement: guidelines for reporting observational studies. BMJ. 2007; 335(7624):806-8

16. Ministry of health of the people's Republic of China. Vaccination work specification. Available from: http://www.nhc.gov.cn/ewebeditor/ uploadfile/2014/02/20140221170607365.doc. Accessed 10 Jan 2019 (in Chinese).

17. Schillie S, Walker T, Veselsky S, Crowley S, Dusek C, Lazaroff J, et al. Outcomes of infants born to women infected with hepatitis B. Pediatrics. 2015;135(5):e1141-7.

18. Zhang L, Gui XE, Teter C, Zhong HR, Pang ZY, Ding LX, et al. Effects of hepatitis $B$ immunization on prevention of mother-to-infant transmission of hepatitis $B$ virus and on the immune response of infants towards hepatitis B vaccine. Vaccine. 2004:32(46):6091-7.

19. Lee CF, Gong Y, Brok J, Boxall EH, Gluud C. Effect of hepatitis B immunisation in newborn infants of mothers positive for hepatitis B surface antigen: systematic review and meta-analysis. BMJ. 2006;332(7537):328-36.

20. Committee on infectious diseases, Committee on fetus and newborn. Elimination of perinatal hepatitis B: providing the first vaccine dose within 24 hours of birth. Pediatrics. 2017;140:e20171870.

21. Borgia G, Carleo MA, Gaeta GB, Gentile I. Hepatitis B in pregnancy. World J Gastroenterol. 2012;18(34):4677-83.

22. Njei B, Gupta N, Ewelukwa O, Ditah I, Foma M, Lim JK. Comparative efficacy of antiviral therapy in preventing vertical transmission of hepatitis $\mathrm{B}$ : a network meta-analysis. Liver Int. 2016:36(5):634-41.

23. Jourdain G, Ngo-Giang-Huong N, Harrison L, Decker L, Khamduang W, Tierney $\mathrm{C}$, et al. Tenofovir versus placebo to prevent perinatal transmission of hepatitis B. N Engl J Med. 2018;378:911-23.

24. Pan CQ, Duan ZP, Dai E, Zhang OS, Han GR, Wang YM, et al. Tenofovir to prevent hepatitis B transmission in mothers with high viral load. N Engl J Med. 2016:374(24):2324-34.

25. Patel MK, Capeding RZ, Ducusin JU, Castro MQ, Garcia LC, Hennessey K. Findings from a hepatitis B birth dose assessment in health facilities in the Philippines: opportunities to engage the private sector. Vaccine. 2014;32(39):5140-4.

26. Hu YS, Wang XJ, Chen YS, Liu W, Zhang RZ, Cui FQ, et al. Study on hepatitis $B$ birth dose coverage in the western and mid-level provinces of China. Chin J Vacc Immu. 2006:12(2):88-90.

27. Stevens CE, Toy P, Kamili S, Taylor PE, Tong MJ, Xia GL, et al. Eradicating hepatitis $B$ virus: the critical role of preventing perinatal transmission. Biologicals. 2017;50:3-19.

28. Gagneur A, Pinguier D, Quach C. Immunization of preterm infants. Hum Vaccines Immunother. 2015;11(11):2556-63.

29. Zhang L, Ko S, LV JJ, Ji F, Yan B, Xu F, et al. Perinatal hepatitis B prevention program in Shandong Province, China: evaluation and progress. Hum Vaccines Immunother. 2014;10(9):2755-60.

30. Losonsky GA, Wasserman SS, Stephens I, Mahoney F, Armstrong P, Gumpper K, et al. Hepatitis B vaccination of premature infants: a reassessment of current recommendations for delayed immunization. Pediatrics. 1999;103(2):E14.

31. World Health Organization. Hepatitis B vaccines: WHO position paper - July 2017. Wkly Epidemiol Rec. 2017;92(27):369-92.

32. Hou JL, Cui FQ, Ding Y, Dou XG, Duan ZP, Han GR, et al. Management algorithm for interrupting mother to child transmission of hepatitis $B$ virus. Clin Gastroenterol Hepatol. 2018. https://doi.org/10.1016/j.cgh.2018.10.007. Available from: https://www.cghjournal.org/article/S1542-3565(18)31090-5/ pdf. Accessed 9 Jan 2019. 